\title{
Lasmiditan for the treatment of acute migraine: a review and potential role in clinical practice
}

This article was published in the following Dove Press journal: Journal of Pain Research

\author{
Jessica C Oswald \\ Nathaniel M Schuster \\ UCSD Center for Pain Medicine, \\ La Jolla, CA, USA
}

Correspondence: Jessica C Oswald UCSD Center for Pain Medicine, 9400 Campus Point Road, Ist Floor, La Jolla, CA 92037, USA

Email Jessica.OswaldEM@gmail.com

\begin{abstract}
Now that the vascular hypothesis of migraine is no longer the prevailing theory of migraine pathogenesis, there is interest in developing acute migraine treatments that act exclusively on non-vascular targets. There is a large percentage of non-responders to current acute migraine treatments and the vasoconstriction associated with triptans limit their use in patients with pre-existing cardiovascular risk factors. Preferential 5-HT 1 agonists have shown promising results in in vitro and early proof-of-concept trials. Lasmiditan, a highly selective $5-\mathrm{HT}_{1 \mathrm{~F}}$ agonist, has completed two Phase III randomized, double blind, placebo-controlled clinical trials, with a third - a long-term, open-label safety study - still underway. Research to date suggests lasmiditan lacks vasoconstrictive properties and may be a safe and effective treatment option in patients refractory to current acute migraine medications or who have cardiovascular risk factors.

Keywords: lasmiditan, 5HT-1F, migraine, headache, serotonin
\end{abstract}

\section{Brief introduction on $5-\mathrm{HT}_{\mathrm{IF}}$ receptors as novel targets in the treatment of migraine}

Migraine is a pathophysiologically complex disease. Current evidence suggests that migraine is a neuronal process involving activation and sensitization of the trigeminal nociceptors and the trigeminocervical complex, as well as cortical spreading depression and abnormal brainstem activity. ${ }^{1,2}$ During a migraine, there is meningeal vessel dilatation, an observation that was once believed to be the cause of migraine ${ }^{3}$ but is now thought to be an epiphenomenon..$^{3-5}$

Triptans, selective $5-\mathrm{HT}_{1 \mathrm{~B} / \mathrm{D}}$ agonists, were initially developed when migraine was believed to be a "vascular headache" and triptans' ability to activate the $5-\mathrm{HT}_{1 \mathrm{~B}}$ and $5-\mathrm{HT}_{1 \mathrm{D}}$ receptors on cerebral vessels and induce cerebral vessel vasoconstriction was desired. ${ }^{3}$ Triptans are currently a first-line treatment for acute migraine. Their activity works not only on cerebral vessels but also on cardiac endothelial cells, causing cardiac vasoconstriction. ${ }^{3,6}$ It is reported that $76 \%$ of patients taking oral sumatriptan experience heavy arms and $50 \%$ experience chest pressure, ${ }^{7}$ but this chest pain is nonischemic. ${ }^{8}$ While ischemic events attributable to triptans are uncommon, ${ }^{8}$ there are case reports of myocardial infarctions and strokes after initiation of sumatriptan..$^{9-11}$ Non-steroidals, which are also often used for acute migraine treatment, have been associated with increased risk of myocardial infarction. ${ }^{12}$

Triptans are contraindicated in patients with cardiovascular disease, cerebrovascular disease, uncontrolled hypertension, and hemiplegic migraine. ${ }^{6,12}$ With emerging evidence that cerebral vasodilation is not the nociceptive stimulus in migraine, attention has 
turned to developing new acute migraine treatments targeting the trigeminal pathways while avoiding the vasoactive $5-\mathrm{HT}_{1 \mathrm{~B}}$ and $5-\mathrm{HT}_{1 \mathrm{D}}$ receptors. The $5-\mathrm{HT}_{1 \mathrm{~F}}$ receptor has become a receptor of interest as a putative migraine treatment target. Lasmiditan, a 5-HT ${ }_{1 \mathrm{~F}}$ agonist, has successfully completed Phase III clinical trials and holds promise as an emerging acute migraine treatment.

There are existing summaries on lasmiditan, ${ }^{13-16}$ however no prior review includes results from the Phase III GLADIATOR trial. This paper summarizes all results and information on lasmiditan available as of July 2018.

\section{Review of pharmacology, mode of action, pharmacokinetics, and administration of lasmiditan Pharmacology}

Lasmiditan, previously known as COL-144 and LY573144, is a highly selective $5-\mathrm{HT}_{1 \mathrm{~F}}$ agonist. Structurally different than triptans, this compound constitutes a new class of drugs, "ditans". Whereas triptans possess an indole structure that closely resembles the 5-HT receptor, ditans replace this indole group with a pyridine-piperidine scaffold. Triptans non-specifically bind to the $5-\mathrm{HT}_{1 \mathrm{~B}}$ and $5-\mathrm{HT}_{1 \mathrm{D}}$ receptors and with varying affinity bind the $5-\mathrm{HT}_{1 \mathrm{~F}}$ receptors, causing direct vascular vasoconstriction. ${ }^{17}$ In contrast, ditans are selective for the $5-\mathrm{HT}_{1 \mathrm{~F}}$ receptor and its mechanism of action is neuronal without evidence of vasoactive effects. In pre-clinical and clinical models believed to mimic human cerebral and cardiovascular contractility, ${ }^{18} 5-\mathrm{HT}_{1 \mathrm{~F}}$ agonists have not been associated with rabbit saphenous vein ${ }^{17,19}$ or cat carotid artery ${ }^{18}$ vasoconstriction.

\section{Mode of action}

In the current prevailing theory of migraine pain, trigeminal activation triggers the release of signaling proteins including CGRP, causing secondary cerebral vessel dilation, plasma protein extravasation, and mast cell degranulation. ${ }^{4,20-22}$ While triptans are potent $5-\mathrm{HT}_{1 \mathrm{~B} / \mathrm{D}}$ agonists, they also exhibit partial $5-\mathrm{HT}_{1 \mathrm{~F}}$ activity and act upon neuronal pathways. ${ }^{17}$ Some researchers suggest that the efficacies of triptans are in part due to their activity on the $5-\mathrm{HT}_{1 \mathrm{~F}}$ receptor. ${ }^{20}$ Using established animal models of migraine, $5-\mathrm{HT}_{1 \mathrm{~F}}$ receptor agonists showed decreased plasma protein extravasation ${ }^{17}$ as well as c-fos expression, ${ }^{20}$ and suppressed neuronal firing within the trigeminal nucleus caudalis. ${ }^{23}$

Lasmiditan is a highly selective $5-\mathrm{HT}_{1 \mathrm{~F}}$ agonist, having a greater than 450 -fold increased affinity for $5-\mathrm{HT}_{1 \mathrm{~F}}$ over $5-\mathrm{HT}_{1 \mathrm{~A}}, 5-\mathrm{HT}_{1 \mathrm{~B}}$ and 5-HT $\mathrm{HD}_{\mathrm{D}}$ receptors. Moreover, lasmiditan has been shown to have low potency for the vasoactive $5-\mathrm{HT}_{1 \mathrm{~B}}$ and 5-HT ${ }_{1 \mathrm{D}}$ receptors. ${ }^{17}$ Importantly, the 5-HT $\mathrm{HF}_{1 \mathrm{~F}}$ receptor is not found on vascular structures and lasmiditan has not been shown to have vasoconstrictive effects. ${ }^{17}$

\section{Plasma protein extravasation}

Neurogenic inflammation of the dura is an important cause of migraine pain. ${ }^{24}$ The $5-\mathrm{HT}_{1 \mathrm{~F}}$ receptors are found in high density in the neurons of the trigeminal ganglion. The release of pain-provoking stimuli (including calcitonin gene-related peptide and substance P) from the presynaptic membrane of the trigeminal system can be indirectly measured by quantifying protein extravasation from dura mater following painful stimulation. ${ }^{25}$ Johnson et al showed that extravasation of dura plasma proteins in guinea pigs was unaffected by the $5-\mathrm{HT}_{1 \mathrm{~B} / \mathrm{D}}$ receptors but significantly decreased with increasing $5-\mathrm{HT}_{1 \mathrm{~F}}$ receptor affinity. ${ }^{20}$ Lasmiditan has been shown to block plasma protein extravasation. ${ }^{17}$

\section{C-fos}

$\mathrm{C}$-fos is a protein that regulates the transcription rate of genes and is used as an indicator of the level of synaptic activation. After painful stimuli, c-fos is measured in high levels within the trigeminal nerve complex. ${ }^{17}$ With repetitive noxious stimuli, it is believed that the persistently elevated levels of c-fos trigger long-lasting transcription changes. ${ }^{26} 5-\mathrm{HT}_{1 \mathrm{~F}}$ agonists have been shown to decrease c-fos activity within the trigeminal nucleus. ${ }^{27}$ Rats pretreated with lasmiditan have shown decreased c-fos expression in the nucleus caudalis. ${ }^{17}$

\section{Suppression of neuronal firing in the trigeminal nucleus caudalis}

Shepheard et al observed a $5-\mathrm{HT}_{1 \mathrm{~F}}$ dose response decrease in action potential generation in response to electrical dural stimulation, suggesting that $5-\mathrm{HT}_{1 \mathrm{~F}}$ agonists inhibit second order neurons in the trigeminal nucleus caudalis. ${ }^{23}$

\section{Pharmacokinetics}

There are limited data on the pharmacokinetics of lasmiditan. During Phase I clinical trials, the peak drug concentrations (Cmax), time at peak concentration (Tmax), area under the curve from administration to time 30 hours (AUC[0-t]) and area under the curve from pre-dose to infinity (AUC[0-inf]) were measured in fed and fasted states. The Cmax $(\mathrm{ng} / \mathrm{mL})$ and Tmax (hours) with $200 \mathrm{mg}$ of lasmiditan were $394.7 \mathrm{ng} /$ $\mathrm{mL}$ and 2.5 hours in the fed state and $322.8 \mathrm{ng} / \mathrm{mL}$ and 1.5 hours in the fasted state. The AUC(0-t) and AUC(0-inf) were 
higher in the fed $(2,244 \mathrm{ng} . \mathrm{h} / \mathrm{mL}, 2,265 \mathrm{ng} . \mathrm{h} / \mathrm{mL})$ than the fasted states $(1,892 \mathrm{ng} . \mathrm{h} / \mathrm{mL}, 1,906 \mathrm{ng} . \mathrm{h} / \mathrm{mL})$ respectively. ${ }^{15}$ It is not known whether the differences observed in the fed and fasted states have clinical significance.

Early Phase II clinical trials evaluated intravenous (IV) formulations of lasmiditan but there are currently no Phase III trials for IV lasmiditan underway. Three doses of oral lasmiditan have been studied in Phase III clinical trials: 50, 100 , and $200 \mathrm{mg}$.

\section{Efficacy studies, including any comparative studies and relevant case reports LY334370}

Early studies evaluating the effectiveness of preferential agonists of the $5-\mathrm{HT}_{1 \mathrm{~F}}$ receptor were favorable. A randomized, placebo-controlled, double blind, parallel-design migraine study evaluating LY334370, a strong agonist of 5-HT showed a clinically significant dose response. Single oral doses of 20,60, or $200 \mathrm{mg}$ were used and end points were 2-hour response, 2-hour pain free, sustained response and sustained pain free response. Dosages of 60 and $200 \mathrm{mg}$ were better than placebo on all measured outcomes, and the 200 $\mathrm{mg}$ dose was more effective than the $60 \mathrm{mg}$ dose. Patients who took 60 and $200 \mathrm{mg}$ had improved 2-hour headache response rates ( $50 \%$ vs $71 \%$ ), were more likely to be pain free after 2 hours ( $27 \%$ vs 38\%), and achieved higher sustained headache response rates ( $37 \%$ vs 52\%). These findings were statistically significant $(P<0.05)$ when compared to placebo's 2-hour headache response rate $(19 \%)$, pain free rate $(4 \%)$, and sustained headache response rate $(8 \%)$. Adverse reactions (parenthesis, somnolence, dizziness, and asthenia) were more likely in the therapeutic dosages (60 and $200 \mathrm{mg}$ ) than in the placebo and $20 \mathrm{mg}$ groups. ${ }^{28}$

While LY334370 showed promising results, it exhibited partial 5-HT ${ }_{1 \mathrm{~A}}$ affinity. ${ }^{17}$ Efforts were made to develop an agent with even more preferential affinity for the $5-\mathrm{HT}_{1 \mathrm{~F}}$ receptor.

\section{Preclinical pharmacological profile of lasmiditan}

\section{Receptor affinity}

Following the positive Phase II clinical trial of LY334370, lasmiditan was developed as an even more selective and structurally different $5-\mathrm{HT}_{1 \mathrm{~F}}$ receptor agonist. Early preclinical pharmacologic in vitro studies showed that lasmiditan and LY334370 were potent 5-HT ${ }_{1 F}$ agonists, however the preference for the $5 \mathrm{HT}_{1 \mathrm{~F}}$ receptor compared to other 5-HT receptors was greatest with lasmiditan. While LY334370 had over eight times the affinity for the $5 \mathrm{HT}_{1 \mathrm{~F}}$ compared to the $5-\mathrm{HT}_{1 \mathrm{~A}}$ receptor, lasmiditan's preferential affinity for the $5-\mathrm{HT}_{1 \mathrm{~F}}$ receptor was 475 times that for the $5-\mathrm{HT}_{1 \mathrm{~A}}$ and $5-\mathrm{HT}_{1 \mathrm{~B}}$ receptors and over 270-fold higher than for all 5-HT receptors evaluated $\left(5-\mathrm{HT}_{1 \mathrm{~A}}, 5-\mathrm{HT}_{1 \mathrm{~B}}, 5-\mathrm{HT}_{1 \mathrm{D}}, 5-\mathrm{HT}_{1 \mathrm{E}}, 5-\mathrm{HT}_{2 \mathrm{~A}}, 5-\mathrm{HT}_{2 \mathrm{~B}}\right.$, $5 \mathrm{HT}_{2 \mathrm{C}}, 5-\mathrm{HT}_{6}$, and $\left.5-\mathrm{HT}_{7}\right) .{ }^{17}$

\section{Vasoconstriction}

Lasmiditan showed no binding affinity across receptors known to regulate vasoconstriction. In a pre-clinical study using rabbit saphenous veins as a model for human coronary arteries, no contraction was identified with $100 \mu \mathrm{mol}$ of lasmiditan whereas $50 \%$ contractility was noted with the equivalent dose of sumatriptan.

\section{In vitro migraine models}

Using the in vitro migraine models described in the "Mode of action" section, oral administration of lasmiditan showed decreased plasma protein extravasation and decreased c-fos levels in rat brains and yielded similar results when compared to a triptan (rizatriptan). ${ }^{17}$

\section{Phase I clinical trials}

Between 2003 and 2018, 14 completed Phase I clinical trials have been conducted, however there are currently no peer-reviewed publications. Presented results of a Phase I clinical trial comparing QT/QTc of two doses of lasmiditan to moxifloxacin showed that neither the therapeutic (100 mg) nor supratherapeutic dose (400 mg) had QT/QTc prolonging effects, whereas moxifloxacin exhibited the expected prolonged QT/QTc. Comparison of EKGs with oral doses of $100 \mathrm{mg}$ and $400 \mathrm{mg}$ of lasmiditan did not show arrhythmias. ${ }^{29}$

\section{Phase II clinical trials}

Two Phase II clinical trials were performed in 2006 and 2009 , each with an associated peer-reviewed publication. The first study (ID NCT00384774, COL MIG-201) aimed to test the efficacy of IV lasmiditan and evaluate the effective dose range. Using a prospective, randomized, double blind, placebo-controlled design, 130 healthy study participants between the ages of 18-65 with moderate to severe migraines were given adjusted doses of IV lasmiditan or placebo. The doses ranged form $2.5 \mathrm{mg}$ to $45 \mathrm{mg}$ and were given to small cohorts (five or six people) and adjusted based on the response rates or adverse events experienced with the preceding group. The primary end point was the reduction of a moderate to severe headache to mild or none after 2 hours of initiation of study dose. The most effective dose based on the primary end point was $20 \mathrm{mg}$ of IV lasmiditan. There was a 
statistically significant 2-hour headache response rate with $20 \mathrm{mg}(P=0.048)$ and $30 \mathrm{mg}(P=0.017)$ of lasmiditan when compared to placebo, whereas the 2 -hour headache response rate for the $10 \mathrm{mg}$ dose was not statistically significant compared to that of placebo (Table 1). The linear trend of 2-hour headache response observed with escalating doses of IV lasmiditan $10 \mathrm{mg}$ (54\%), $20 \mathrm{mg}$ (64\%), $30 \mathrm{mg}$ (69\%), and $45 \mathrm{mg}(75 \%)$ when compared to placebo (45\%) (Figure 1) was statistically significant $(P=0.01)$. There were no serious adverse events reported. Subjects did not experience common triptan side effects such as chest pain or chest pressure. The most common side effects were parasthesias and dizziness with no clear dose-related response. ${ }^{30}$

The second Phase II clinical trial (ID NCT00883051, COL MIG-202) evaluated the safety and efficacy of oral lasmiditan in acute migraine. In this randomized, double blind, placebo-controlled, dose ranging study, otherwise healthy patients between the ages of 18-65 were randomized to either oral lasmiditan $(50,100,200$ or $400 \mathrm{mg})$ or placebo in a 1:1:1:1:1 ratio (Table 2). Of the 378 participants included in the study, 297 received lasmiditan. The percentage of headache responders measured by improvement from moderate or severe to mild or none after 2 hours was statistically significant when compared to placebo (26\%) for the $50 \mathrm{mg}$ (43\%, $P=0.022), 100 \mathrm{mg}$ (64\%, $P=0.0001), 200 \mathrm{mg}$
(51\%, $P=0.0018)$, and $400 \mathrm{mg}(65 \%, P=0.0001)$ doses of lasmiditan. The percentage of patients who were pain free at 2 hours was not statistically significant when compared to placebo $(7.4 \%)$ at the lower oral doses of $50 \mathrm{mg}(14 \%$, $P=0.18)$ and $100 \mathrm{mg}(14 \%, P=0.19)$ but was significant with the higher $200 \mathrm{mg}(19 \%, P=0.032)$ and $400 \mathrm{mg}$ doses $(28 \%, P=0.0007) .^{31}$

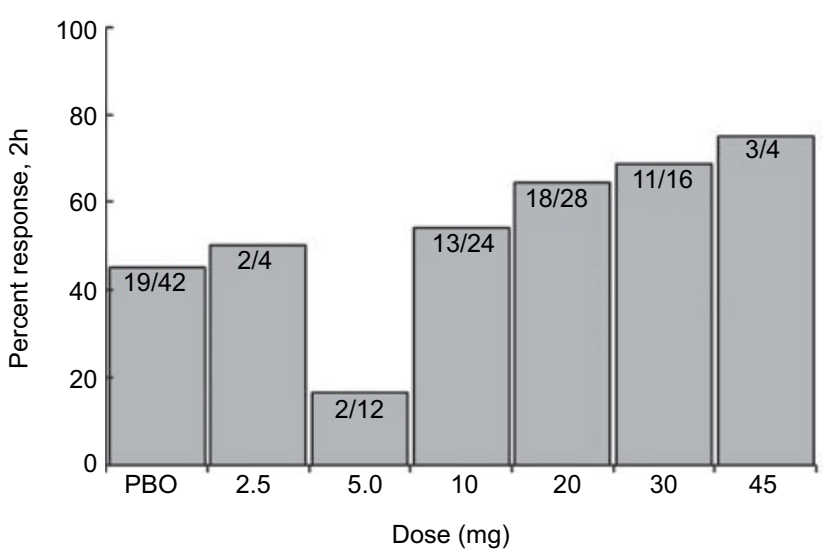

Figure I Proportion of patients with headache relief 2 hours after lasmiditan infusion.

Note: Ferrari MD, Färkkilä M, Reuter U, et al, Cephalalgia, volume 30(10), pages II70-II78, copyright (? 2010 by SAGE Publications. Reprinted by Permission of SAGE Publications, Ltd. $^{30}$

Abbreviation: $\mathrm{PBO}$, placebo.

Table I Summary of results from COL MIG-20I

\begin{tabular}{|c|c|c|c|c|c|c|c|}
\hline IV dose & $2.5 \mathrm{mg} \mathrm{IV}$ & 5 mg IV & I0 mg IV & $20 \mathrm{mg} \mathrm{IV}$ & $30 \mathrm{mg}$ IV & 45 mg IV & Placebo \\
\hline Number of study subjects & 4 & 12 & 24 & 28 & 16 & 4 & 42 \\
\hline 2 hours headache pain freedom (\%) & $0(0)$ & $0(0)$ & $5(20.8)$ & $8(28.8)$ & $6(37.5)$ & I (25) & $8(19)$ \\
\hline Headache pain relief (\%) & $2(50)$ & $2(16.7)$ & I3 (54.2) & $18(64.3)$ & II (68.8) & $3(75)$ & $19(45.2)$ \\
\hline Dizziness n (\%) & $2(50.0)$ & I (8.3) & $8(33.3)$ & $7(25.0)$ & $3(18.8)$ & I (25.0) & $6(14.3)$ \\
\hline Paresthesia $\mathrm{n}(\%)$ & 0 & 0 & $5(20.8)$ & $8(28.8)$ & $7(43.8)$ & I (25.0) & 0 \\
\hline Fatigue $\mathrm{n}(\%)$ & 0 & $\mathrm{I}(8.3)$ & I (4.2) & $5(17.9)$ & $3(18.8)$ & $0(0 \%$ & $4(9.5)$ \\
\hline
\end{tabular}

Note: Ferrari MD, Färkkilä M, Reuter U, et al, Cephalalgia, volume 30(10), pages II70-I 178, copyright @ 2010 by SAGE Publications. Reprinted by Permission of SAGE Publications, Ltd. ${ }^{30}$

Table 2 Results summary of COL MIG-202, SAMURAI, and SPARTAN

\begin{tabular}{|c|c|c|c|c|c|}
\hline Oral dose & $50 \mathrm{mg}$ & $100 \mathrm{mg}$ & $200 \mathrm{mg}$ & $400 \mathrm{mg}$ & Placebo \\
\hline \multicolumn{6}{|l|}{ COL MIG-202 } \\
\hline Number of subjects: & 79 & 81 & 69 & 68 & 81 \\
\hline 2 hours headache pain freedom (\%) & 13.9 & 13.6 & $18.8^{\mathrm{a}}$ & $27.9^{a}$ & 7.4 \\
\hline Headache pain relief (\%) & $43.0^{\mathrm{a}}$ & $64.1^{\mathrm{b}}$ & $50.7^{\mathrm{b}}$ & $64.7^{\mathrm{b}}$ & 25.9 \\
\hline \multicolumn{6}{|l|}{ SAMURAI } \\
\hline 2 hours headache pain freedom (\%) & --- & $28.2^{\mathrm{b}}$ & $32.2^{\mathrm{b}}$ & --- & 15.3 \\
\hline MBS freedom (\%) & --- & $40.9^{b}$ & $40.7^{\mathrm{b}}$ & --- & 29.5 \\
\hline \multicolumn{6}{|l|}{ SPARTAN } \\
\hline 2 hours headache pain freedom (\%) & $28.6^{b}$ & $31.4^{\mathrm{b}}$ & $38.8^{\mathrm{b}}$ & --- & 21.3 \\
\hline MBS freedom (\%) & $40.8^{\mathrm{b}}$ & $44.2^{\mathrm{b}}$ & 48.7 & --- & 33.5 \\
\hline
\end{tabular}

Notes: Headache pain relief at 2 hours. Data from these studies. ${ }^{31-33}$ a $P<0.05$ (compared to placebo). ${ }^{\text {b }}<<0.005$ (compared to placebo).

Abbreviation: MBS, most bothersome symptoms. 


\section{Phase III trials}

Lasmiditan has been studied in three Phase III clinical trials. The two double blind, placebo-controlled, randomized controlled trials that have been completed have presented results. The one ongoing study, an open-label, long-term safety study, has reported interim results. These three studies have not yet been published in the peer-reviewed literature.

\section{SAMURAI (ID NCT02439320, COL MIG-30I)}

The first Phase III clinical trial is SAMURAI. This prospective randomized, double blind, placebo-controlled, parallelgroup study aimed to evaluate the efficacy of two doses of lasmiditan compared to placebo for acute migraine. Primary end points were headache freedom at 2 hours post-dose and secondary end points were headache relief, use of rescue medication, headache recurrence, relief of the most bothersome symptom (nausea, photophobia, phonophobia), and safety. The study enrolled its last of 1,856 patients in July 2016.

While not yet published in the peer-reviewed literature, early, partial results have been presented. The percentages of patients with 2-hour headache relief were statistically significant $(P<0.05)$ when compared to placebo $(43 \%)$ for $100(59 \%)$ and $200 \mathrm{mg}$ doses of lasmiditan (59\%). Similarly (Table 2), the 2-hour headache-free rates were statistically significant $(P<0.05)$ for the $100 \mathrm{mg}(28.2 \%)$ and $200 \mathrm{mg}$ (32.2\%) doses when compared to placebo (15.3\%). Approximately $41 \%$ of patients had relief of the most bothersome symptom in both 100 and $200 \mathrm{mg}$ groups compared to $30 \%$ with placebo $(P<0.05)$.

One patient who took two doses of $100 \mathrm{mg}$ lasmiditan reported palpitations and another who took $100 \mathrm{mg}$ of study drug followed by placebo reported tachycardia. Details of these events were not reported. Consistent with the Phase II trials, the most common side effect was dizziness, reported in $12.5 \%$ and $16.3 \%$ of those in the 100 and $200 \mathrm{mg}$ group, respectively. 32

\section{SPARTAN (ID NCT02605 I74, COL MIG-302)}

With a similar study design as well as primary and secondary outcomes as SAMURAI, SPARTAN evaluated three doses of lasmiditan $(50,100$, and $200 \mathrm{mg}$ ) compared to placebo in the treatment of acute migraine. In contrast to SAMURAI's participants who were healthy, SPARTAN did not exclude patients with coronary artery disease, cardiac arrhythmias or uncontrolled hypertension.

In 2017, SPARTAN reached its primary and secondary end points in all three doses evaluated (Table 2). The percentage of patients who were pain free 2 hours after administration of $50 \mathrm{mg}(28.6 \%), 100 \mathrm{mg}(31.4 \%)$, and $200 \mathrm{mg}$ (38.8\%) of lasmiditan was statistically significantly different $(P<0.005)$ when compared to placebo $(21.3 \%)$. Improvements of the most bothersome symptom 2 hours post-treatment were statistically significant when compared to placebo (33.5\%) with $50 \mathrm{mg}(40.8 \%, P=0.003), 100 \mathrm{mg}$ (44.2\%, $P<0.001)$, and $200 \mathrm{mg}(48.7 \%, P<0.001)$ doses of lasmiditan. ${ }^{33}$ A limitation of SPARTAN for demonstrating safety in people with cardiovascular risk factors is that subjects only used a single dose of lasmiditan; the study does not demonstrate cardiovascular safety with repeated doses.

\section{GLADIATOR (ID NCT02565I86, COL MIG-305)}

A prospective, open-label study evaluating the safety and tolerability of lasmiditan, GLADIATOR, enrolled participants who completed the SAMURAI or SPARTAN trials. The study started in October 2015 and was expected to continue through May 2018. Subjects were randomized to receive either 100 $\mathrm{mg}$ or $200 \mathrm{mg}$ of oral lasmiditan.

The primary end points are the proportion of patients who experienced adverse events and the proportion of migraine attacks associated with adverse events. Secondarily, researchers aim to evaluate the proportion of attacks treated with study drug 2 hours post-treatment.

In 2016, preliminary GLADIATOR results were presented at the fifth European Headache and Migraine Trust International Congress. At that time, approximately 1,100 of the anticipated 2,500 participants were enrolled. Approximately $20 \%$ of patients taking both 100 and $200 \mathrm{mg}$ of lasmiditan experienced side effects. Consistent with prior studies, dizziness was the most commonly reported side effect. No cardiovascular events or side effects have been observed or reported. ${ }^{34}$

\section{Safety profile and patient selection}

The safety profile of lasmiditan was published in Phase II clinical trials. In COL MIG-202, study participants were monitored for adverse events and safety. Vitals signs, laboratory studies, and EKGs did not show any clinically significant drug-related morbidities. Most of the adverse events were mild or moderate in intensity, the percentage of severe adverse events increased with dose 50 (20\%), 100 (28\%), 200 (39\%), and $400 \mathrm{mg}$ (44\%), respectively. Dizziness was the most frequently reported severe adverse event ${ }^{31}$ and is consistent with the preliminary findings of the Phase III trials (Table 3) ${ }^{32-34}$ It is likely that the side effect of dizziness will be dose-limiting in some patients and lead to discontinuation 
Table 3 Summary of side effects

\begin{tabular}{|c|c|c|c|c|c|c|c|c|c|c|}
\hline \multirow{2}{*}{$\begin{array}{l}\text { Study name } \\
\text { Dose }\end{array}$} & \multicolumn{5}{|c|}{ COL MIG-202 (P II) } & \multicolumn{3}{|c|}{ SAMURAI (P II) } & \multicolumn{2}{|c|}{ GLADIATOR (P III) } \\
\hline & $50 \mathrm{mg}$ & $100 \mathrm{mg}$ & $200 \mathrm{mg}$ & $400 \mathrm{mg}$ & Placebo & $100 \mathrm{mg}$ & $200 \mathrm{mg}$ & Placebo & $100 \mathrm{mg}$ & $200 \mathrm{mg}$ \\
\hline $\mathrm{n}$ & 82 & 82 & 71 & 70 & 86 & 630 & 609 & 617 & 558 & 597 \\
\hline Dizziness n (\%) & $20(24.3)$ & $29(35.4)$ & $29(35.4)$ & $38(54.2)$ & $0(0)$ & 75 (II.9) & $95(15.4)$ & $19(3.1)$ & $36(48)$ & $40(67)$ \\
\hline Paresthesia n (\%) & $3(3.6)$ & II (13.4) & $16(22.5)$ & $29(27.1)$ & $2(2.3)$ & $36(5.7)$ & $46(7.6)$ & $13(2.1)$ & $7(15)$ & I (2) \\
\hline Somnolence n (\%) & II (I3.4) & $12(14.6)$ & $10(14.0)$ & $10(14.2)$ & $3(3.5)$ & $33(5.2)$ & $32(5.3)$ & $14(2.3)$ & $2(2)$ & $8(12)$ \\
\hline Fatigue n (\%) & $15(18.2)$ & $24(29.3)$ & $26(36.6)$ & $23(32.9)$ & $3(3.5)$ & $24(3.8)$ & $18(3)$ & $\mathrm{I}(0.2)$ & $14(16)$ & $10(17)$ \\
\hline Nausea n (\%) & $7(8.5)$ & $8(9.8)$ & $3(4.2)$ & $5(7.1)$ & $0(0)$ & $16(2.5)$ & $29(4.8)$ & $9(1.5)$ & $15(2 \mid)$ & $18(39)$ \\
\hline Lethargy n (\%) & ---- & ---- & ---- & ---- & ---- & 12 (I.9) & $14(2.3)$ & I (0.2) & $4(4)$ & $5(7)$ \\
\hline
\end{tabular}

Note: Data from these studies. ${ }^{31,32,34}$

Abbreviation: $\mathrm{P}$, phase of clinical trial.

of lasmiditan in other patients. No chest pain or chest symptoms were reported in the Phase II clinical trials. ${ }^{31}$

While in the Phase II clinical trials and the Phase III SAMURAI study, participants were healthy without cardiovascular risk factors, the Phase III SPARTAN clinical trial enrolled patients with pre-existing cardiovascular disease. Peer-reviewed results of the Phase III studies have not yet been published, but preliminary data report no chest pain or cardiovascular side effects. ${ }^{32-34}$ This is in contrast to the $76 \%$ of patients taking oral sumatriptan who experience heavy arms and the $50 \%$ with chest pressure. ${ }^{7}$ The long-term tolerability remains to be seen but preliminary results suggest lasmiditan holds promise for patients with pre-existing cardiovascular disease or who do not tolerate triptans due to side effects.

\section{Patient focused perspectives such as quality of life, patient satisfaction/ acceptability, adherence, and uptake}

According to the American Migraine Prevalence and Prevention Study, $40 \%$ of episodic migraine patients identified themselves as having at least one of the following: severe headache-related disability (47\%), dissatisfaction with current treatment regimens (32\%), excessive opioid use (32\%) or history of cardiovascular events (26.2\%). ${ }^{35}$ Moreover, $35 \%$ of participants in clinical trials do not benefit from oral triptans. ${ }^{35}$ There is a need for additional acute migraine treatment options. Preliminary results suggest that lasmiditan may be a new safe and effective option for acute migraine treatment, especially for patients refractory to or unable to tolerate triptans, and/or for patients with pre-existing cardiovascular disease.

\section{Conclusions, place in therapy}

Triptans are the current standard-of-care treatment for acute migraines not responsive to over-the-counter medications. Unfortunately, there are a high percentage of patients who do not respond to triptans, do not tolerate triptans, or have contraindications to triptans. In a meta-analysis of 133 randomized controlled trials of triptans, standard dose triptans provided $42 \%-76 \%$ 2-hour pain relief and $18 \%-50 \%$ pain freedom. ${ }^{36}$ As such, there is a need for additional safe and effective acute migraine treatments. Clinical trials for lasmiditan to date have been promising, and lasmiditan appears to avoid typical triptan side effects. While preclinical work suggests that lasmiditan does not cause vasoconstriction, clinical evidence to date is insufficient to conclude the safety of lasmiditan with long-term use in patients with cardiovascular risk factors, and especially not in patients with a history of coronary artery disease or stroke. While lasmiditan's Phase III studies are not yet published, the results reported to date suggest that lasmiditan is more effective than placebo in the treatment of acute migraine with 2-hour pain freedom and 2-hour pain relief rates similar to those seen in oral triptan studies. With Eli Lilly \& Co. having announced plans to apply for US FDA approval in early 2018, lasmiditan may soon be a new addition to the expanding headache armamentarium.

\section{Disclosure}

Nathaniel M Schuster has a research collaboration with Eli Lilly \& Co. not related to lasmiditan. The authors have not received funding for the generation of this manuscript. The authors report no conflicts of interest in this work.

\section{References}

1. Schulte LH, May A. The migraine generator revisited: continuous scanning of the migraine cycle over 30 days and three spontaneous attacks. Brain. 2016;139(Pt 7):1987-1993.

2. May A, Schulte LH. Chronic migraine: risk factors, mechanisms and treatment. Nat Rev Neurol. 2016;12(8):455-464.

3. Humphrey PP, Feniuk W, Perren MJ, Beresford IJ, Skingle M, Whalley ET. Serotonin and migraine. Ann NY Acad Sci. 1990;600(600):587-598 discussion 598-600.

4. Pietrobon D, Moskowitz MA. Pathophysiology of migraine. Annu Rev Physiol. 2013;75:365-391. 
5. Akerman S, Holland PR, Goadsby PJ. Diencephalic and brainstem mechanisms in migraine. Nat Rev Neurosci. 2011;12(10):570-584.

6. Maassenvandenbrink A, Reekers M, Bax WA, Ferrari MD, Saxena PR. Coronary side-effect potential of current and prospective antimigraine drugs. Circulation. 1998;98(1):25-30.

7. Visser WH, Jaspers NM, de Vriend RH, Ferrari MD. Chest symptoms after sumatriptan: a two-year clinical practice review in 735 consecutive migraine patients. Cephalalgia. 1996;16(8):554-559.

8. Dodick D, Lipton RB, Martin V, et al. Consensus statement: cardiovascular safety profile of triptans (5-HT agonists) in the acute treatment of migraine. Headache. 2004;44(5):414-425.

9. O'Connor P, Gladstone P. Oral sumatriptan-associated transmural myocardial infarction. Neurology. 1995;45(12):2274-2276.

10. Jayamaha JE, Street MK. Fatal cerebellar infarction in a migraine sufferer whilst receiving sumatriptan. Intensive Care Med. 1995;21(1):82-83.

11. Abbrescia VD, Pearlstein L, Kotler M. Sumatriptan-associated myocardial infarction: report of case with attention to potential risk factors. J Am Osteopath Assoc. 1997;97(3):162-164.

12. Bally M, Dendukuri N, Rich B, et al. Risk of acute myocardial infarction with NSAIDs in real world use: bayesian meta-analysis of individual patient data. $B M J .1909 ; 2017(357) \mathrm{j}$.

13. Raffaelli B, Israel H, Neeb L, Reuter U. The safety and efficacy of the 5-HT $1 \mathrm{~F}$ receptor agonist lasmiditan in the acute treatment of migraine. Expert Opin Pharmacother. 2017;18(13):1409-1415.

14. Capi M, de Andrés F, Lionetto L, et al. Lasmiditan for the treatment of migraine. Expert Opin Investig Drugs. 2017;26(2):227-234.

15. Negro A, Koverech A, Martelletti P. Serotonin receptor agonists in the acute treatment of migraine: a review on their therapeutic potential J Pain Res. 2018;11:515-526.

16. Vila-Pueyo M. Targeted 5-HT ${ }_{1 \mathrm{~F}}$ Therapies for Migraine. Neurotherapeutics. 2018;15(2):291-303.

17. Nelson DL, Phebus LA, Johnson KW, et al. Preclinical pharmacological profile of the selective 5-HT1F receptor agonist lasmiditan. Cephalalgia. 2010;30(10):1159-1169.

18. Goadsby PJ, Classey JD. Evidence for serotonin (5-HT)1B, 5-HT1D and 5-HT1F receptor inhibitory effects on trigeminal neurons with craniovascular input. Neuroscience. 2003;122(2):491-498.

19. Cohen ML, Schenck K. 5-Hydroxytryptamine(1F) receptors do not participate in vasoconstriction: lack of vasoconstriction to LY344864, a selective serotonin $(1 \mathrm{~F})$ receptor agonist in rabbit saphenous vein. J Pharmacol Exp Ther. 1999;290(3):935-939.

20. Johnson KW, Schaus JM, Durkin MM, et al. 5-HT1F receptor agonists inhibit neurogenic dural inflammation in guinea pigs. Neuroreport. 1997;8(9-10):2237-2239.

21. Charles A. Advances in the basic and clinical science of migraine. Ann Neurol. 2009;65(5):491-498.

22. Goadsby PJ, Lipton RB, Ferrari MD. Migraine--current understanding and treatment. $N$ Engl J Med. 2002;346(4):257-270.

23. Shepheard S, Edvinsson L, Cumberbatch M, et al. Possible antimigraine mechanisms of action of the $5 \mathrm{HT} 1 \mathrm{~F}$ receptor agonist LY334370. Cephalalgia. 1999;19(10):851-858.
24. Markowitz S, Saito K, Moskowitz MA. Neurogenically mediated leakage of plasma protein occurs from blood vessels in dura mater but not brain. J Neurosci. 1987;7(12):4129-4136.

25. Adham N, Bard JA, Zgombick JM, et al. Cloning and characterization of the guinea pig 5-HT1F receptor subtype: a comparison of the pharmacological profile to the human species homolog. Neuropharmacology. 1997;36(4-5):569-576.

26. Anton F, Herdegen T, Peppel P, Leah JD. c-FOS-like immunoreactivity in rat brainstem neurons following noxious chemical stimulation of the nasal mucosa. Neuroscience. 1991;41(2-3):629-641.

27. Hunt SP, Pini A, Evan G. Induction of c-fos-like protein in spinal cord neurons following sensory stimulation. Nature. 1987;328(6131): 632-634.

28. Goldstein DJ, Roon KI, Offen WW, et al. Selective seratonin 1F (5-HT(1F)) receptor agonist LY334370 for acute migraine: a randomised controlled trial. Lancet. 2001;358(9289):1230-1234.

29. CoLucid Pharmaceuticals Details Phase 3 Development Strategy for Lasmiditan to Address Major Unmet Needs in Acute Migraine Therapy [webpage on the Internet]. Durham NC: Pappas Ventures; 2018 Available from: http://www.pappasventures.com/2012/09/18/colucidpharmaceuticals-details-phase-3-development-strategy-lasmiditanaddress-major-unmet-needs-acute-migraine-therapy/. Accessed August $10,2018$.

30. Ferrari MD, Färkkilä M, Reuter U, et al. Acute treatment of migraine with the selective 5-HT1F receptor agonist lasmiditan--a randomised proof-of-concept trial. Cephalalgia. 2010;30(10):1170-1178.

31. Färkkilä M, Diener HC, Géraud G, et al. Efficacy and tolerability of lasmiditan, an oral 5-HT(1F) receptor agonist, for the acute treatment of migraine: a phase 2 randomised, placebo-controlled, parallel-group, dose-ranging study. Lancet Neurol. 2012;11(5):405-413.

32. SAMURAI: Lasmiditan Reduces Pain in Acute Migraine; 2018. Available from: https://globenewswire.com/news-release/2016/09/06/869611/0/en/ CoLucid-Pharmaceuticals-Announces-Achievement-of-Both-Primaryand-Key-Secondary-Endpoints-in-the-SAMURAI-Phase-3-PivotalTrial-of-Lasmiditan-in-Migraine.html. Accessed March 19, 2018.

33. Lilly Announces Positive Results for Second Phase 3 Study of Lasmidi$\tan$ for the Acute Treatment of Migraine (NYSE:LLY); 2018. Available from: https://investor.lilly.com/static-files/15cflefc-da8f-485c-90016ff3b432b129. Accessed March 19, 2018.

34. CoLucid Pharmaceuticals Provides Interim Update on GLADIATOR [webpage on the Internet]. GlobeNewswire, Inc.; 2016. Available from: https:/globenewswire.com/news-release/2016/09/19/872772/0/en/ CoLucid-Pharmaceuticals-Provides-Interim-Update-on-GLADIATOR. html. Accessed August 10, 2018.

35. Lipton RB, Buse DC, Serrano D, Holland S, Reed ML. Examination of unmet treatment needs among persons with episodic migraine: results of the American Migraine Prevalence and Prevention (AMPP) Study. Headache. 2013;53(8):1300-1311.

36. Cameron C, Kelly S, Hsieh SC, et al. Triptans in the Acute Treatment of Migraine: A Systematic Review and Network Meta-Analysis. Headache. 2015;55 Suppl 4:221-235.
Journal of Pain Research

\section{Publish your work in this journal}

The Journal of Pain Research is an international, peer reviewed, open access, online journal that welcomes laboratory and clinical findings in the fields of pain research and the prevention and management of pain. Original research, reviews, symposium reports, hypothesis formation and commentaries are all considered for publication.

\section{Dovepress}

The manuscript management system is completely online and includes a very quick and fair peer-review system, which is all easy to use. Visit http://www.dovepress.com/testimonials.php to read real quotes from published authors. 